\title{
PENDEKATAN TEKNOLOGI DAN INFORMASI DALAM PERANCANGAN PUSAT INOVASI MOBIL MASA DEPAN
}

\author{
Steven Giovanni ${ }^{11}$, Doddy Yuono ${ }^{21}$
}

1)Program Studi S1 Arsitektur, Fakultas Teknik, Universitas Tarumanagara, stevengiovanni1996@gmail.com

2) Program Studi S1 Arsitektur, Fakultas Teknik, Universitas Tarumanagara, masdoddyuono@gmail.com

\begin{abstract}
Abstrak
Generasi milenial terlahir dimana dunia sudah modern dan teknologi yang sudah canggih mulai diperkenalkan ke publik dimana industri hiburan sudah meningkat dan dipengaruhi oleh internet. Beragam tentang sifat atau karakteristik dari generasi ini dan yang paling utama generasi ini memiliki peningkatan dalam penggunaan teknologi serta media digital dan lebih menyukai mempelajari sesuatu dengan penggunaan hal visual. Perkembangan teknologi yang pesat sangat berpengaruh dalam kehidupan milenial. Salah satu hal yang terdapat hubungan dengan peningkatan teknologi pada zaman ini adalah di bidang otomotif. Produsen merek kendaraan mobil mulai bersaing dalam mengeluarkan konsep mobil masa depan dimana kendaraan mobil yang mengedepankan sistem fitur teknologi dan fitur konektivitas. Oleh sebab itu, perkembangan kendaraan mobil terus berkembang hingga saat ini dari jenis kendaraan mobil konvensional hingga kendaraan mobil masa depan (future cars). Dengan menciptakan kendaraan mobil masa depan, generasi ini dapat merasakan kepuasan dalam berkendara dan dapat merasakan performa atau kualitas dari kendaraan mobil tersebut dan yang paling penting adalah dapat merasakan kenyamanan dan kenikmatan dalam berkendara dengan fitur teknologi yang semakin canggih. Dengan adanya sudut pandang yang ada, proyek untuk generasi milenial ini adalah "Pusat Inovasi Mobil Masa Depan" dengan memberikan fasilitas program berupa pengetahuan akan desain dan kelebihan dari mobil masa depan dengan cara penyampaian yang mendepankan sistem teknologi dengan sifat yang atraktif dan inovatif.
\end{abstract}

Kata kunci: Atraktif; Inovatif; Kreatif; Masa Depan; Otomotif

\begin{abstract}
Millennials are born where the world is modern and sophisticated technology has been introduced to the public where the entertainment industry has increased and is influenced by the internet. Diverse about the nature or characteristics of this generation and most of all this generation has an increase in the use of technology and digital media and prefers to learn something with the use of visuals. Rapid technological developments are very influential in millennial life. One of the things that has a connection with improving technology in this era is in the automotive sector. Manufacturers of car vehicle brands began to compete in issuing the concept of a future car where car vehicles prioritize system technology features and connectivity features. Therefore, the development of car vehicles continues to grow to date from the types of conventional car vehicles to future cars. By creating a car vehicle of the future, this generation can feel satisfaction in driving and can feel the performance or quality of the vehicle and the most important thing is to be able to feel the comfort and pleasure in driving with increasingly sophisticated technological features. With the existing viewpoint, the project for this millennial generation is the "Future Car Innovation Center" by providing program facilities in the form of knowledge of the design and advantages of future cars by delivering a technology system that is attractive and innovative.
\end{abstract}

Keywords: Automotive; Attractive; Creative; Future; Innovative

\section{PENDAHULUAN}

Generasi milenial merupakan salah satu kelompok generasi yang cukup banyak hidup di dunia pada zaman ini. Generasi ini terlahir dimana dunia sudah modern dan teknologi yang sudah canggih mulai diperkenalkan ke publik dimana industri hiburan sudah meningkat dan dipengaruhi oleh internet. Beragam tentang sifat atau karakteristik dari generasi ini. Yang 
paling utama adalah generasi ini memiliki peningkatan dalam penggunaan teknologi serta media digital dan lebih menyukai mempelajari sesuatu dengan penggunaan hal visual. (Fourhooks, 2015)

Perkembangan teknologi yang pesat sangat berpengaruh dalam kehidupan milenial. Salah satu hal yang terdapat hubungan dengan peningkatan teknologi pada zaman ini adalah di bidang otomotif. Produsen merek kendaraan mobil mulai bersaing dalam mengeluarkan konsep mobil masa depan dimana kendaraan mobil yang mengedepankan sistem fitur teknologi dan fitur konektivitas. Otomotif sedang berkembang di dunia ini agar terdapat kendaraan yang ramah lingkungan. Generasi milenial percaya bahwa 5-10 tahun ke depan pembuatan kendaraan mobil masa depan dengan harga yang terjangkau akan meningkat dengan seiringnya waktu berjalan. Di Indonesia kendaraan mobil ini sedang dalam tahap pengenalan dimana kendaraan ini mulai berkembang setiap tahunnya. Presiden sudah mengeluarkan peraturan untuk kendaraan mobil masa depan yang berisi di UU 22 tahun 2017 tentang Rencana Umum Energi Nasional dimana sudah mulai disiapkan tempat untuk pengisian daya kendaraan listrik. Program untuk rencana ke depan di Indonesia adalah mengembangkan kendaraan mobil masa depan pada tahun 2025 sebesar 2200 unit kendaraan roda empat dan 2,1 juta untuk kendaraan roda dua.

Kendaraan mobil merupakan salah satu kebutuhan dalam kehidupan dimana dengan adanya kendaraan mobil manusia akan lebih mudah dalam menjalankan aktivitas sehari-hari. Oleh sebab itu, perkembangan kendaraan mobil terus berkembang hingga saat ini dari jenis kendaraan mobil konvensional hingga kendaraan mobil masa depan (future cars). Dengan adanya perkembangan kendaraan mobil ini membuat kendaraan yang ramah lingkungan yang dapat mengurangi dampak buruk dalam pembuangan gas $\mathrm{Co}$.

\section{KAJIAN LITERATUR}

\section{Definisi Generasi Milenial}

Generasi Milenial atau dikenal juga sebagai Gen Y adalah kelompok demografi setelah Gen $X$ dimana menurut para ahli, generasi ini hadir pada tahun 1981 sebagai awal kelahiran hingga tahun 1994. Penelitian menunjukkan bahwa usia pada generasi millennial berkisar dari umur 18 tahun hingga 34 tahun. Generasi ini terlahir dimana dunia sudah modern dan teknologi canggih yang diperkenalkan ke publik dimana industri hiburan sudah meningkat dan dipengaruhi oleh internet. Menurut Biro sensus di Amerika menyebutkan bahwa populasi generasi millennial pada tahun 2015 adalah 75,3 juta jiwa dan menjadi kelompok generasi terbesar. Tingkat imigrasi generasi ini lebih tinggi dibandingkan generasi yang lain. (Lopez, 2017)

\section{Definisi Otomotif}

Otomotif adalah ilmu yang mempelajari tentang mesin kendaran bermotor (mobil \& motor) dan memiliki berbagai disiplin ilmu yang lebih spesifik tentang komponen dari sistem yang terkandung dalam kendaraan bermotor. Dalam arti lain merupakan ilmu mesin untuk kendaraan bermotor (mobil \& motor) yang terkait dengan hal-hal yang utama dalam mesin mobil yaitu $a c c u$, baterai, ban, mesin, jok.

\section{Perkembangan Kendaraan Mobil}

- Mobil Konvensional

Kendaraan mobil dengan menggunakan bahan bakar minyak (konvensional) karena mesin lebih efisien dalam penggunaan bahan bakar. Kendaraan yang dirancang untuk kebutuhan berkendara sehari-hari sehingga sistem keamanan yang masih standar dan teknologi kendaraan yang belum terlalu canggih. 


\section{- Mobil Hybrid}

Kendaraan mobil yang sudah mulai efisien dan ramah lingkungan dimana teknologi sudah mulai berkembang pada kendaraan mobil. Kendaraan dengan sistem hybrid ini merupakan kendaraan yang memiliki 2 generator dalam mesin yaitu sistem bahan bakar minyak (konvensional) dan sistem baterai yang dapat diisi ulang dengan cara charge seperti gadget. Cara kerja mobil hybrid ini adalah motor listrik tenaga baterai akan hidup ketika bahan bakar mobil sudah habis sehingga sistem kendaraan mobil ini akan lebih irit dalam bahan bakar dan rendah emisi gas buang.

- Mobil masa depan

Kendaraan mobil yang sudah dalam tahap pengenalan konsep yaitu desain kendaraan mobil dalam jangka waktu ke depan. Desain mobil masa depan ini akan meningkatkan sistem teknologi dan sistem konektivitas pada saat berkendara seperti fungsi display pada layar depan kaca, terintegrasi dengan smartphone, dan adanya konektivitas yang membuat kendaraan bisa saling berinteraksi. Mobil masa depan akan dirancang dengan menggunakan mode autopilot yaitu kendaraan dapat menyetir sendiri tanpa manusia menggunakan stir dimana dapat mengurangi dampak kecelakaan.

\section{Faktor-faktor yang mempengaruhi}

- Sikap dan Karakteristik

Generasi milenial telah lahir dalam keadaan dunia yang sudah modern dan perkembangan teknologi yang canggih sehingga generasi ini sudah terbiasa hidup dengan menggunakan teknologi yang canggih dan salah satunya masuk ke bidang otomotif.

- Memiliki kemampuan yang lebih

Generasi milenial ini memiliki tingkat kemampuan yang lebih tinggi daripada generasi sebelumnya dalam penggunaan teknologi. Generasi ini cenderung lebih responsif dalam penggunaan teknologi.

- Rasa ingin mendapatkan yang lebih

Generasi milenial ini memiliki karakteristik tersebut sehingga membuat generasi ini cenderung untuk mendapatkan sesuatu yang lebih sehingga mereka dapat menggunakannya dan dapat merasakan kepuasan.

- Lingkungan

Dunia yang sudah semakin modern yang sudah menggunakan teknologi canggih atau media digital dalam seluruh aspek kegiatan sehari-hari.

\section{Definisi Ruang Pameran}

Ruang pamer didefinisikan sebagai tempat untuk memamerkan produk tertentu, seperti otomotif, furniture, dll yang berfungsi untuk meningkatkan pemasaran. Fungsi ruang pamer pada biasanya adalah sebagai tempat untuk memamerkan produk barang yang ditawarkan untuk konsumen. Barang yang dapat dipajang dapat berbagai macam seperti barang elektronik, barang furniture, barang otomotif, dll. Ruang pamer harus mempunyai kemampuan untuk memamerkan barang secara maksimal agar pengunjung tertarik terhadap barang yang sedang dipamerkan.

\section{Definisi Ruang Pamer Mobil Independen}

Ruang pamer khusus mobil dimana mobil yang ada tidak selalu bergantung kepada satu merek namun bisa berasal dari berbagai merek. Mobil yang dijual beragam dari berbagai kategori dengan mengutamakan kendaraan yang ramah lingkungan dengan sistem hybrid. Lokasi yang strategis merupakan salah satu faktor penting dari bangunan sebagai pusat bursa mobil dimana dengan memberikan akses jalanan yang besar dan mudah diakses dari berbagai kawasan sehingga mempermudah pengunjung untuk mengetahui dan menemukan lokasi ruang pamer. 


\section{Tipologi Ruang Pameran}

- Tugas

Diarahkan kepada kegiatan transaksi jual-beli, memamerkan bentuk produk, pengetahuan melalui dokumentasi visual agar berfungsi menjadi sumber informasi bagi pengunjung yang datang. (Fachri Muhammad, 2015)

- Fungsi

- Fungsi Pameran (Display)

- Fungsi Ruang Persiapan (Display Preparation)

- Fungsi Pengetahuan (Workshop)

- Kegiatan

- Kegiatan Pameran

- Menyajikan bentuk produk yang dipamerkan secara menarik sehingga membuat pengunjung merasakan kepuasaan dalam mengunjungi kegiatan pameran.

- Kegiatan Workshop

- Memberikan informasi tahap pengenalan tentang unit produksi untuk jangka waktu ke depannya.

- Kegiatan Diskusi

- Membedah tipe produk dengan kegiatan berdiskusi atau kegiatan interaksi antara penjual dengan pengunjung.

- Akomodasi

Akomodasi yang tersedia pada ruang pameran adalah dengan memberikan kemudahan bagi pengunjung yang datang dan juga melengkapi sarana dan prasarana bagi pengunjung berupa kafe, restoran, bookshop, auditorium untuk melakukan kegiatan berdiskusi.

- Prinsip Tata Ruang Pamer

- Tersedia benda objek pameran yang langka

- Menyediakan benda prototype yang merupakan unit produksi untuk jangka waktu ke depannya

- Terdapat after market yang merupakan pameran variasi dari sperpat

- Metode Penyajian Display

- Metode penyajian visual Metode penyajian baik secara 2 dimensi atau 3 dimensi agar pengunjung dapat lebih mengetahui secara jelas mengenai informasi dari jenis-jenis produk.

- Metode penyajian edukatif Memberikan informasi tentang proses pembuatan atau proses penggunaan secara detail produk agar memudahkan pengunjung mendapatkan informasi yang bermanfaat.

\section{METODE}

Metode pengambilan data yang digunakan adalah metode Pattern Language dengan mengambil teknik pendekatan fungsi dan struktur pembentuk dari bidang peristiwa yang terbentuk akibat waktu, tempat, dan manusia. Pattern Language merupakan unsur yang memiliki pola berbeda-beda yang disusun dengan syarat namun tetap memiliki kebebasan yang tak terbatas. Suatu bahasa dapat disimpulkan sebagai komposisi yang dibentuk dalam rangkaian hal yang berbeda. Terdapat 2 komposisi utama yang dirangkai sehingga bisa membentuk suatu bahasa yang terpolakan menjadi pesan yang ingin dikomunikasikan dari tempat tersebut yaitu pattern of event dan pattern of space dimana kedua bentuk tersebut saling membentuk satu sama lain.

Pattern of Event akan menjelaskan fungsi bangunan akan terbentuk akibat adanya faktor dari aktivitas manusia dan kondisi lingkungan sekitarnya sedangkan Pattern of Space menjelaskan bahwa kegiatan/aktivitas manusia di dalam lingkungan tersebut akan membentuk suatu ruang dimana suatu tempat memiliki batasan yang jelas yang bersifat melingkupi yang 
terbentuk karena adanya peran manusia yang bergerak dan membentuk ruang dalam pergerakannya tersebut.

Sehingga dengan pendekatan metode yang ada, digabung dengan proses analisis dan sintesis dalam merancang desain bangunan untuk proyek ini. Penggabungan metode tersebut menghasilkan skema berpikir yang bertujuan untuk menjadi konsep dasar dalam merancang bangunan proyek ini dan dilanjutkan dengan pencarian tipologi-tipologi yang sudah ada agar dari tipologi tersebut dapat menghasilkan program yang tepat untuk bangunan pada proyek ini. Tipologi akan menjadi dasar acuan untuk terbentuknya kegiatan pada program dan besaran luas program yang sesuai untuk proyek yang akan dirancang dan dibangun.

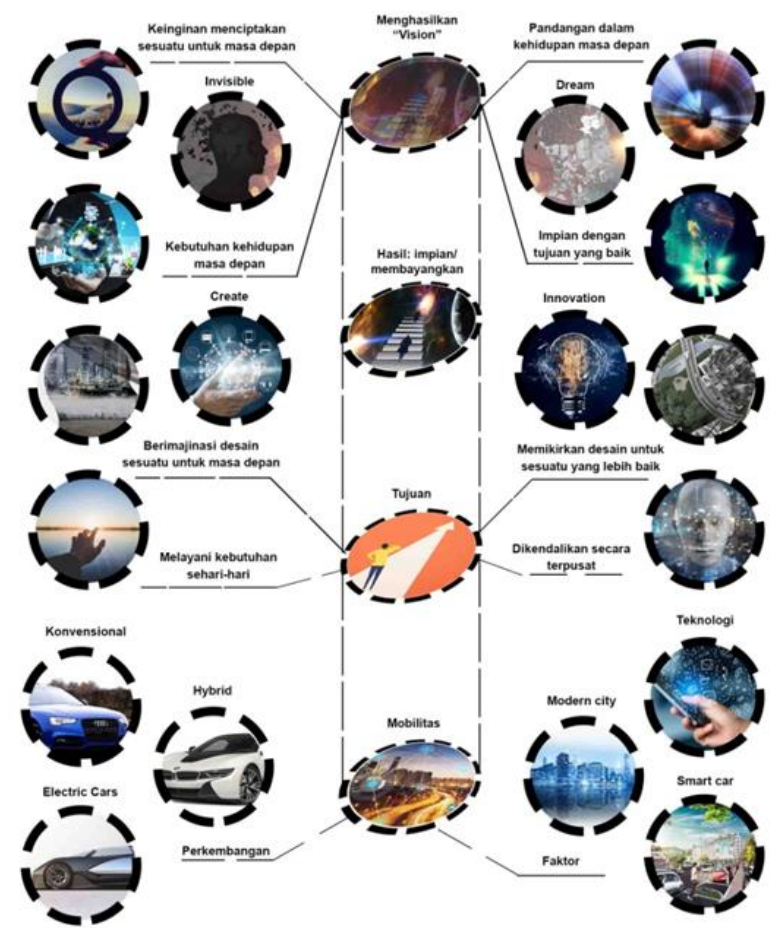

Gambar 1. Skema Berpikir Pendekatan Metode Sumber: Penulis, 2019

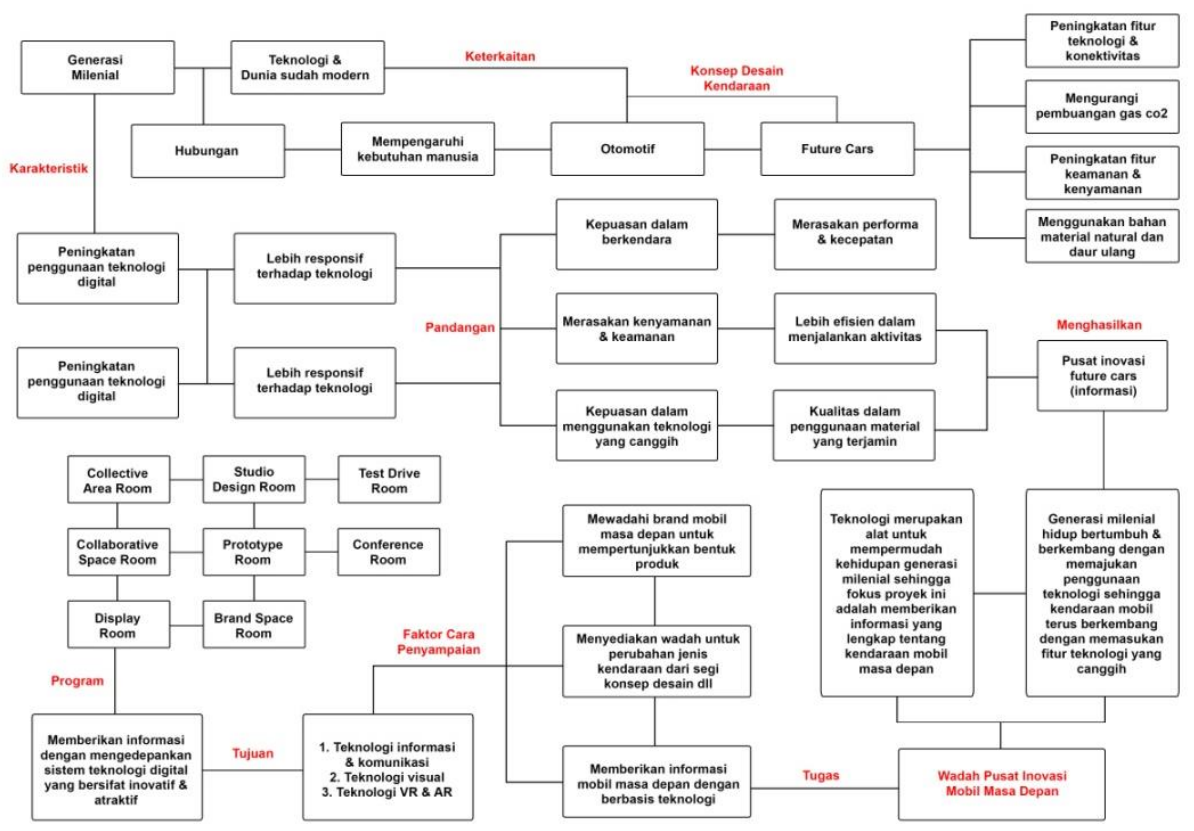

Gambar 2. Skema Berpikir Proyek Sumber: Penulis, 2019 
Menggunakan metode analisis dan sistesis dalam merancang desain bangunan, dari program sampai dengan studi - studi ruang baru yang sesuai dengan tema future. Membuat kerangka berpikir terlebih dahulu dan dilanjutkan dengan menjabarkan tipologi dari tipe bangunan ini.

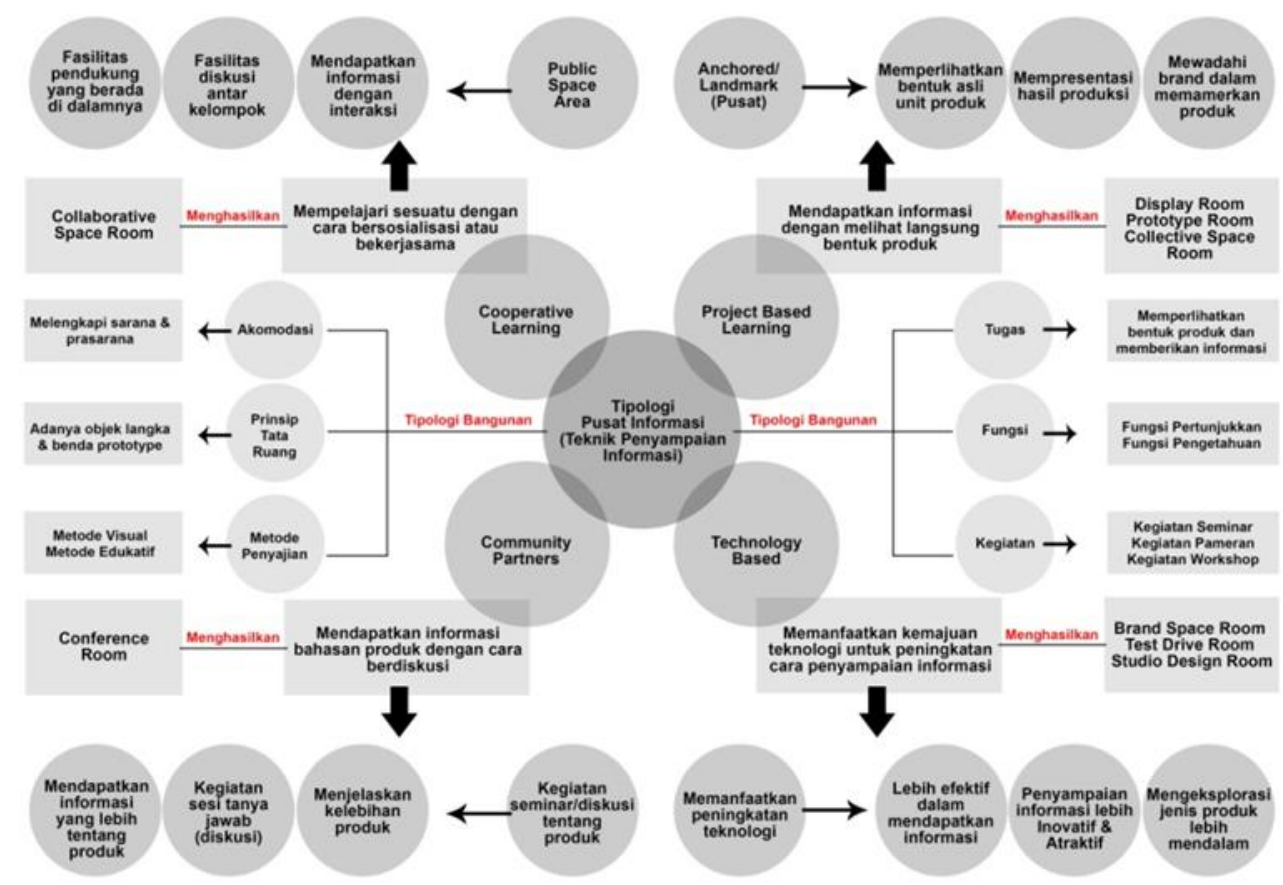

Gambar 3. Kerangka Berpikir Tipologi Bangunan

Sumber: Penulis, 2019

\section{DISKUSI DAN HASIL}

Pusat Inovasi Mobil Masa Depan berlokasi di Jl. Pantai Indah Kapuk, RT.6/R2.2, Kamal Muara, Kec. Penjaringan, Kota Jakarta Utara, Daerah Khusus Ibukota Jakarta 14470. Proyek ini terdiri dari 8 fungsi-fungsi ruang utama sebagai berikut; Area Display, Ruang Studio, Ruang Prototype, Area Uji Coba, Galeri Koleksi, Ruang Diskusi, Ruang Pengenalan Merk Kendaraan Mobil, dan Area Kolaboratif. Dengan adanya program utama tersebut yang didukung dengan fungsi-fungsi program pendukung seperti lobi, ruang diskusi, kafe, restoran, dan area penjualan souvenir. Keseluruhan total luas bangunan $5730 \mathrm{~m} 2$ dimanfaatkan 70 persen sebagai fungsi program utama yang dapat menampung $\pm 400-450$ orang secara bersamaan.

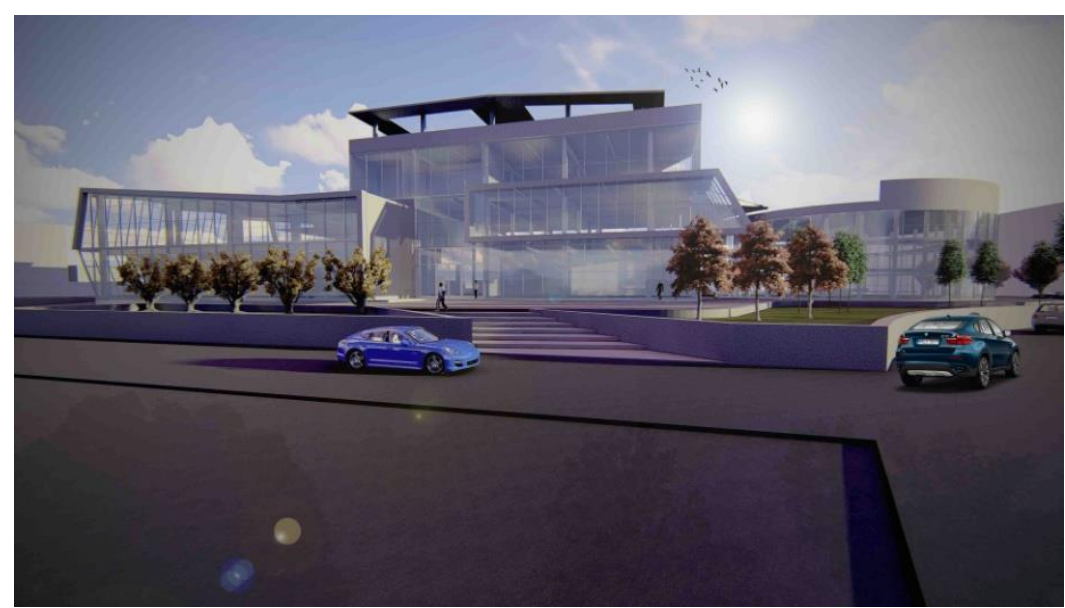

Gambar 4. Gambar 3d Eksterior Terbaik Sumber: Penulis, 2019 

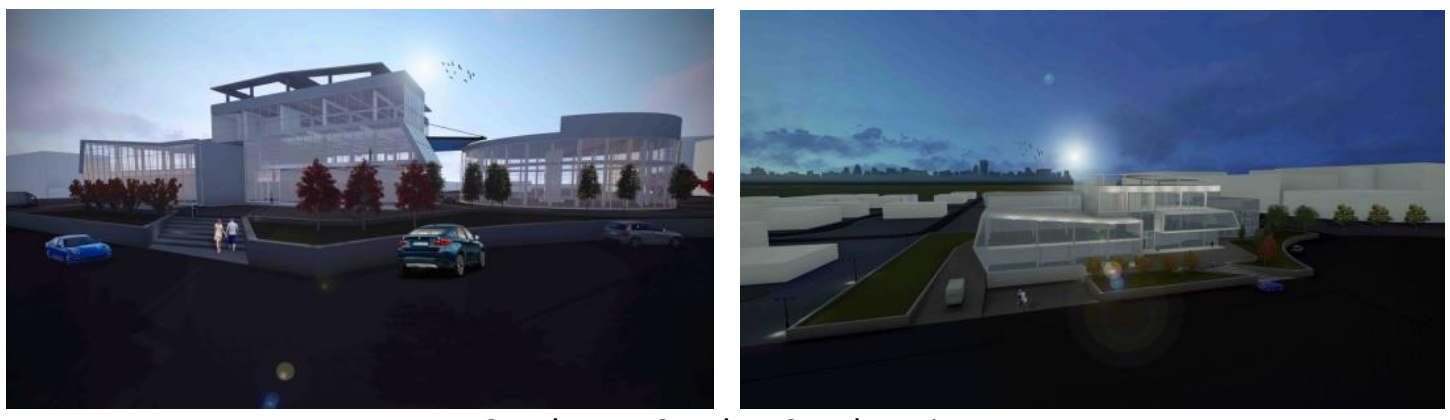

Gambar 5. Gambar 3D Eksterior

Sumber: Penulis, 2019

Bentuk bangunan tersebut dihasilkan dari konsep dan skema berpikir awal yang kemudian dikaji dengan menggunakan metode Pattern Language tersebut sehingga menghasilkan bentuk bangunan yang akan menghasilkan rasa inovatif ketika melihatnya dari luar. Selain itu, bentuk bangunan terbentuk berdasarkan perhitungan tata guna lahan dan disesuaikan berdasarkan hasil analisa lingkungan sekitar. Bentuk bangunan yang memiliki permainan perhitungan derajat agar memberikan dampak inovatif yang dirasakan pengunjung saat berada di dalam bangunan yang akan menjadi key views pada bangunan ini sehingga mengexpose kondisi keadaan yang ada di dalam yang akan menjadi daya tarik pengunjung. Bentuk terakhir yang menyesuaikan fungsi ruangan yang ada di dalamnya.

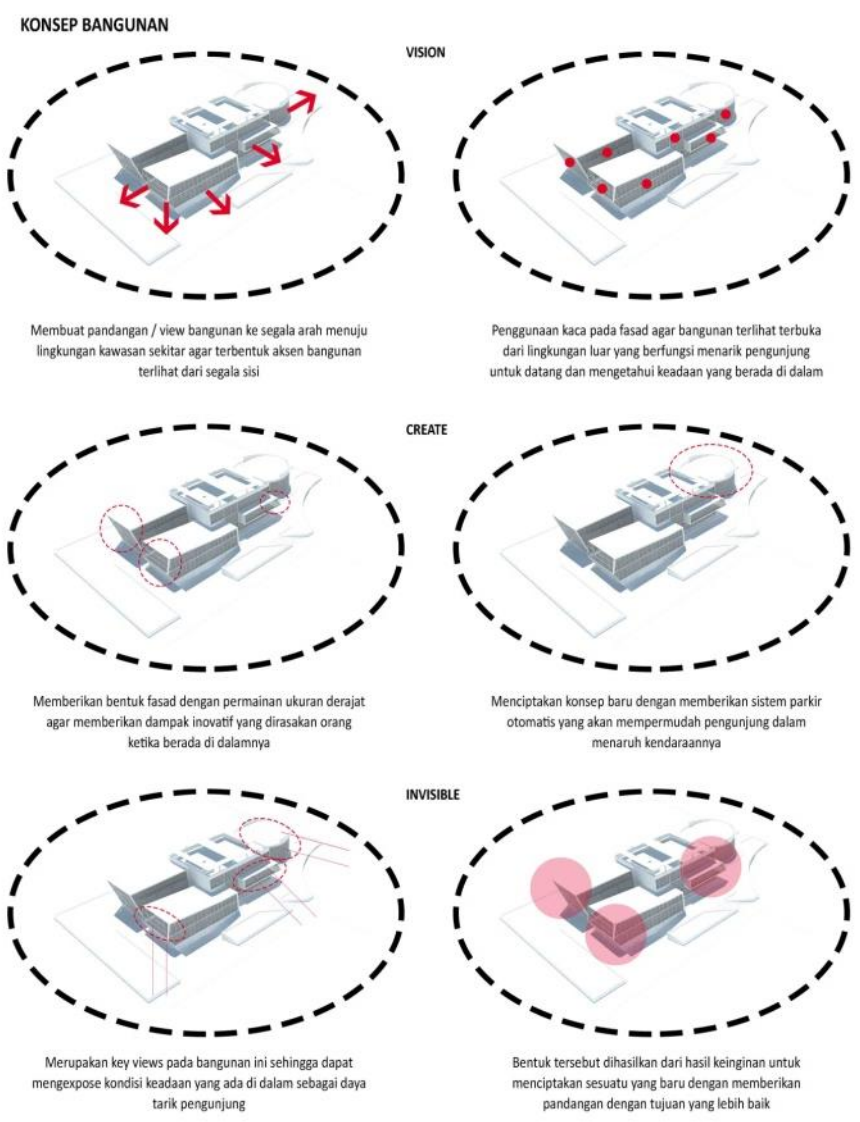

Gambar 6. Konsep Bangunan

Sumber: Penulis, 2019

- Konsep 1 bangunan akan menyesuaikan diri dengan pandangan "vision" dimana view bangunan dibentuk menuju ke segala arah lingkungan kawasan sekitar sehingga dapat terlihat dari segala sisi. 
- Konsep 2 bangunan akan terbentuk "create" agar menciptakan suasana bangunan yang inovatif dengan menggunakan permainan bentuk ukuran derajat pada bagian fasad. Dapat dirasakan oleh pengunjung yang berada di dalam bangunan.

- Konsep 3 bangunan akan terlihat terbuka "invisible" dengan penggunaan kaca sebagai fasad utama bangunan yang memiliki fungsi key views pada bangunan sehingga dapat mengexpose kondisi keadaan yang ada di dalam bangunan sebagai daya tarik pengunjung.

Kesimpulan untuk konsep bangunan ini adalah mengambil satu kata kunci dari karakteristik yang bersifat future/masa depan dimana kata kunci tersebut akan dikembangkan menjadi konsep dan dikembangkan lagi sampai menghasilkan bentuk atau design scheme dari bangunan proyek ini. Satu kata kunci tersebut dihasilkan dari pendekatan metode yang dikaitkan dari karakteristik lingkungan pada sekitar dengan pola aktivitas yang dihasilkan manusia pada area lingkungan ini. Sehingga penggunaan teknologi dalam bangunan ini untuk mendukung kinerja program utama pada proyek bangunan ini. Penggunaan teknologi visual dengan media digital yang akan menyampaikan informasi tentang kendaraan masa depan secara inovatif dan atraktif.

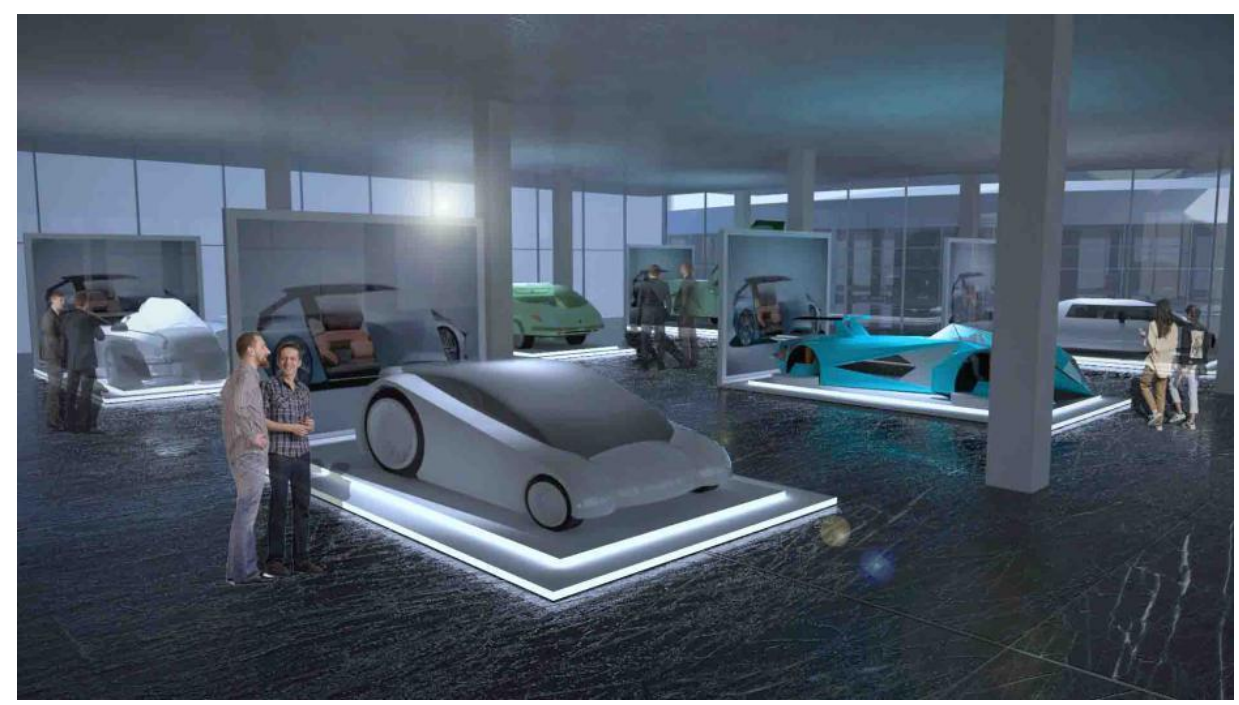

Gambar 7. Gambar 3d Interior Display Area Sumber: Penulis, 2019
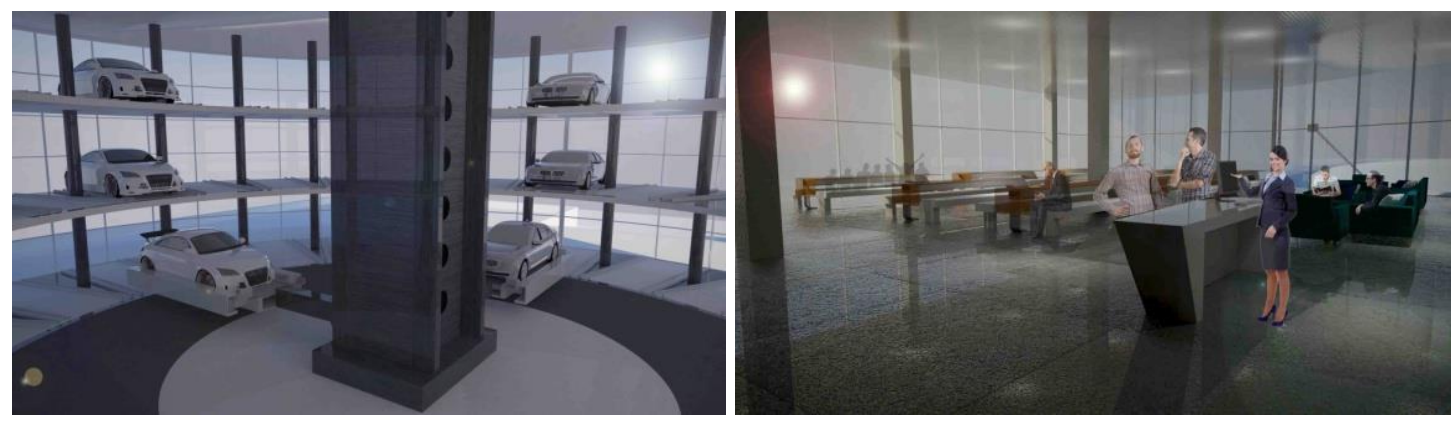

Gambar 8. Gambar 3d Interior

Sumber: Penulis, 2019 


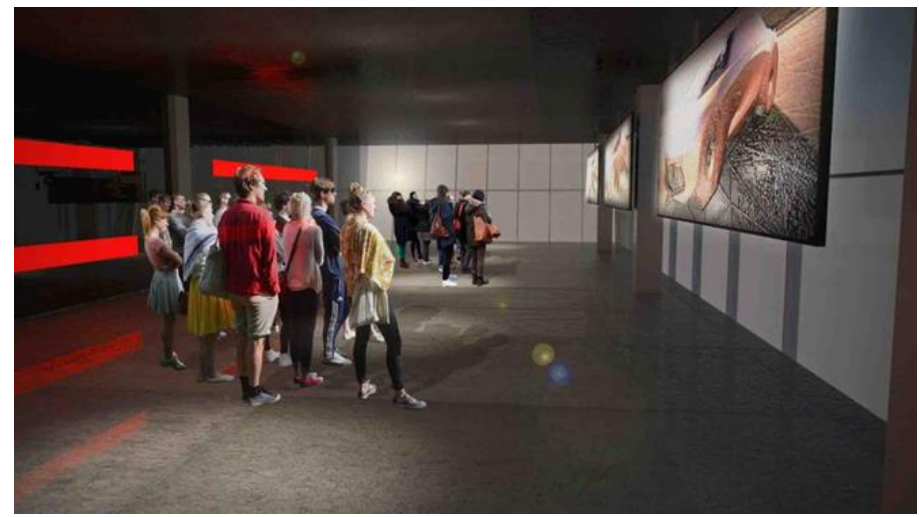

Gambar 9. Gambar 3d Interior

Sumber: Penulis, 2019

Luasan program dan zoning dari bangunan ini dihasilkan dari analisa tipologi-tipologi yang sudah dijabarkan sebelumnya. Zoning pada lantai bawah dibuat program yang lebih publik dan untuk lantai atasnya dibuat program utama dari proyek ini. Suasana dalam bangunan yang di ciptakan modern dengan penggunaan sistem teknologi canggih untuk mengenalkan masyarakat tentang kendaraan mobil masa depan dengan penggunaan teknologi yang menjadi fasilitas pendukungnya.

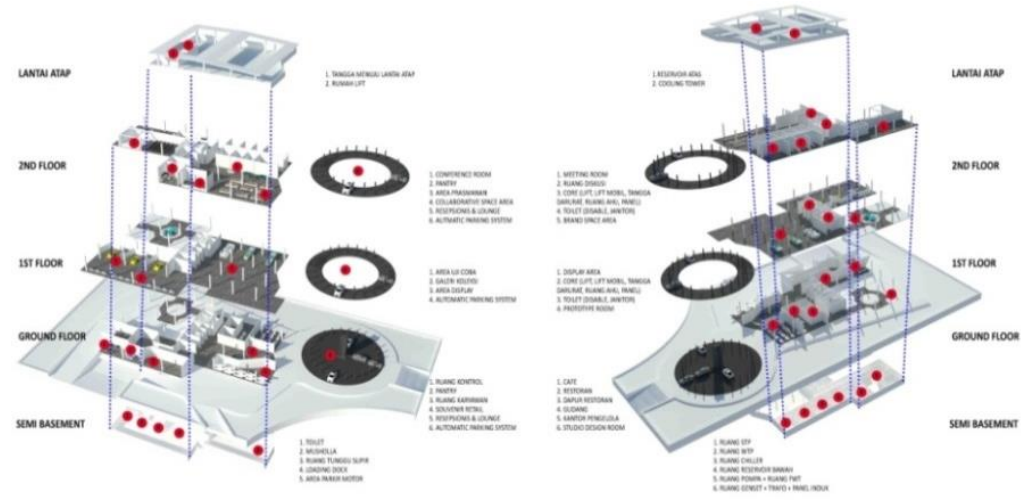

Gambar 10. Gambar Exploded Denah Sumber: Penulis, 2019

Bangunan terdiri dari 3 lantai ditambah 1 semi basement. Semi basement digunakan sebagai fungsi MEP, parkir motor, dan area loading barang. Lantai 1 digunakan sebagai fungsi area publik seperti restoran, kafe, lobi, dan resepsionis. Lantai 2 digunakan sebagai program utama yaitu fungsi area display kendaraan mobil. Lantai 3 digunakan sebagai program pendukung kegiatan utama yaitu area diskusi bersama.

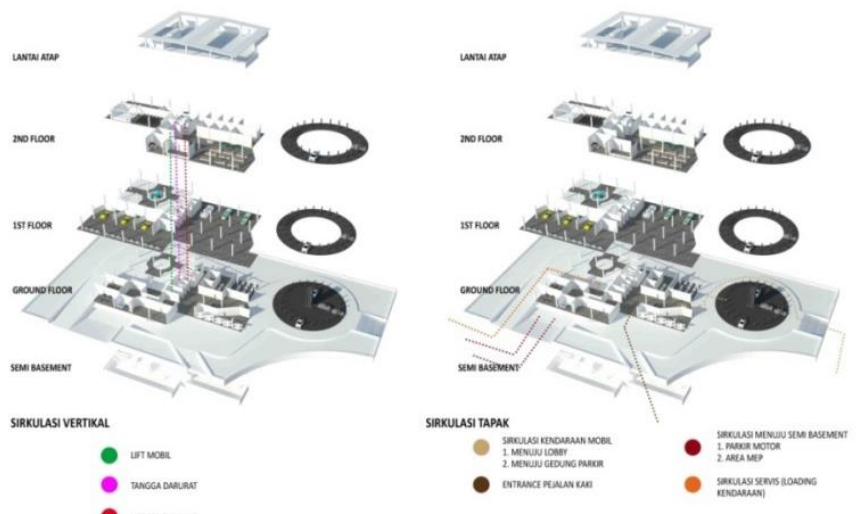

Gambar 11. Gambar Sirkulasi Pengunjung Sumber: Penulis, 2019 


\section{KESIMPULAN DAN SARAN}

Program yang digunakan dihasilkan dari skema berpikir awal dan rangkaian dari tipologi sehingga terbentuk luasan ruang dan kegiatan pada ruangan tersebut. Bentuk bangunan dihasilkan dari konsep bangunan yang akan membuat pengunjung merasakan hal yang berbeda (inovatif, future) ketika di dalam bangunan tersebut sehingga Pusat Inovasi Mobil Masa Depan merupakan sebuah tempat edukasi yang bersifat inovatif bagi kaum milenial dimana bangunan ini menawarkan pengetahuan akan mobil masa depan secara terbaru dengan sifat yang inovatif dan atraktif dengan memberikan informasi secara lengkap cara desain dan kelebihan dari kendaraan masa depan "future car" dengan penggunaan media digital dan teknologi yang canggih dengan memberikan pengalaman yang baru bagi masyarakat milenial Indonesia tentang edukasi yang berbasis hiburan.

\section{REFERENSI}

Bond, M. (2017, Juni 6). The Hidden Ways That Architecture Affects How You Feel. Retrieved www.bbc.com/future/story/20170605-the-psychology-behind-your-citys-design

Fachri M. (2015, Juni 20). Tipologi Hall www.fachrimuhammadabror.wordpress.com/2017/01/28/tipologi-hall

Fourhooks (2015, April 26).The Generation Guide - Millennials, Gen X, Y, Z and Baby Boomers fourhooks.com/marketing/the-generation-guide-millennials-gen-x-y-z-and-baby-boomersart5910718593/

Lopez, N. (2017, April 1). Gen Y: Millennials in Architecture. Retrieved from https://medium.com/studiotmd/gen-y-millennials-in-architecture-476e9839321b

Main D.. (2017, September 8). Who Are the Millennials? https://www.livescience.com/38061-millennials-generation-y.html

Nielsen. (2017). millennials on millennial : A Look At Viewing Behavior, Distraction And Social Media Stars. www.nielsen.com/us/en/insights/news/2017/millennials-on-millennials-alook-at-viewing-behavior-distraction-social-media-stars.html

Sanburn Josh. (2013, May 9). Millennials: The Next Greatest Generation? http://nation.time.com/2013/05/09/millennials-the-next-greatest-generation/

Stein Joel. (2013, May 20). Millennials: The Me Me Me Generation. https://time.com/247/millennials-the-me-me-me-generation/

Tipologi Bangunan. (2017). Tipologi-Tipologi Bangunan www.flanel4world.wordpress.com/tag/tipologi-bangunan

Tjahjono, G. (1999). Peran Arsitektur dan Antropologi dalam Tata Ruang Kota Indonesia Abad ke-21. www.klikgeografi.blogspot.com/2016/12/17-tujuan-pembangunan-berkelanjutansdgs.html

Tujuan Pembangunan Berkelanjutan. (2018). Sustainable Finance www.ojk.go.id/sustainablefinance/id/publikasi/prinsip-dan-kesepakatan-internasional/Pages/Tujuan-PembangunanBerkelanjutan.aspx

Tujuan Pembangunan Berkelanjutan. (2017). Sustainable Finance

Vidler, A. (1977). The Third Typology. Oppsitions, 7-16. 